\title{
O paradoxo da transmissão familiar do poder ${ }^{1}$
}

\author{
Marie Brossier e Gilles Dorronsoro
}

\begin{abstract}
Resumo: Num sistema político competitivo, a transmissão hereditária do poder é um fenômeno paradoxal. O discurso democrático é de fato meritocrático e implica numa separação das esferas privada e pública. No entanto, em alguns sistemas políticos competitivos, e sem transmissão hereditária legal, as famílias ocupam posições de poder por várias gerações. Embora central em algumas democracias, a dimensão familiar do poder político permanece relativamente inexplorada. Este objeto "não convencional" é abordado aqui a partir de estudos de caso no Sudeste Asiático (Índia), na França (Gironde e Nova Caledônia) e no Líbano. Todos esses exemplos levantam a questão da renovação das elites em antigas ou novas sociedades democráticas e nos convidam a pensar sobre as fronteiras - mais porosas do que parece - entre experiências democráticas, poliarquias e oligarquias.
\end{abstract}

\author{
Plano do artigo \\ 1. Disciplinar o objeto de hereditariedade? \\ 2. Formação de dinastias políticas e constituição de um capital político familiar. \\ 3. Qualificar e desqualificar a hereditariedade na política.
}

\begin{abstract}
Sobre os autores Marie Brossier

Professora do Departamento de Ciência Política da Universidade de Laval, Canadá. O seu trabalho centra-se na reconfiguração das práticas de cidadania na África Ocidental, girando em torno da Sociologia dos Movimentos Sociais, da Sociologia das Instituições e da Política Comparada. Atualmente está desenvolvendo um projeto de pesquisa sobre a transmissão familiar do poder político na África subsaariana (financiamento da FQRSC) e participa de vários programas coletivos de pesquisa que se concentram em eleições e cidadania no Senegal (financiamento da Universidade Paris 1 e da Universidade de Columbia) e sobre a questão da internacionalização da educação na África (financiamento da Agência Nacional de Pesquisa Francesa - Universidade de Bordeaux). Sua tese de doutorado realizada na Universidade Paris 1/Panthéon-Sorbonne, defendida em 2010, intitula-se "Quando a mobilização produz a instituição. Práticas das organizações familiares e religiosas no Senegal"2 está sendo publicada pela editora Karthala. marie.brossier@pol.ulaval.ca
\end{abstract}

\section{Gilles Dorronsoro}

Professor de Ciência Política na Universidade de Paris 1/Pantheon-Sorbonne, membro sênior do Instituto Universitário da França, chefe do projeto ERC (European Research Council) "Dinâmica social das guerras civis". Seu trabalho concentra-se principalmente em questões de identidade e guerras civis. Ele publicou Revolução sem fim: Afeganistão de 1979 até o presente (New York, Columbia University Press, 2005, versão estendida da Revolução Afegã: dos comunistas aos talibãs, Paris, Editora Karthala, 2005); Identidades e políticas: da diferenciação cultural ao conflito (com Olivier Grosjean, Paris, Editora Presses de Sciences Po, 2015); Síria: anatomia de uma guerra civil (com Adam Baczko e Arthur Quesnay, Paris, CNRS Éditions, 2016).

gilles.dorronsoro@univ-paris1.fr

\footnotetext{
${ }^{1}$ Tradução livre de Ana Vanali. Texto original «Le paradoxe de la transmission familiale du pouvoir», Critique internationale, vol. 73, № 4, 2016, p. 9-17. Disponível em https://www.cairn.info/revue-critique-internationale-2016-4-page-9.htm. Acesso 25.outubro.2017. Autorização para a publicação da tradução cedido por Catherine Burucoa, responsável da Revista Critique Internationale (Sciences Po, Centre de Recherches Internationales) no dia 15 de novembro de 2017.
}

2 Original "Pratiques de la famille et organisations religieuses au Sénégal" disponível em http://www.fasopo.org/sites/default/files/ir/th brossier.pdf. Acesso 25.outubro.2017. 


\title{
O paradoxo da transmissão familiar do poder
}

\author{
Marie Brossier e Gilles Dorronsoro
}

Historicamente, a transmissão familiar do poder político está longe de ser universal ou muito estável. Isso é demonstrado, de um lado, pela oposição entre os impérios romano e otomano - onde a instabilidade política surge em parte pela ausência de regras de sucessão ${ }^{3}$ - e de outro lado, pelas realezas ocidentais que estabelecem regras de transmissão vinculativas, cujos sistemas democráticos são, em certo sentido, seus herdeiros ${ }^{4}$. Experimentados no continente europeu, a partir do século XIX, a generalização dos sistemas políticos competitivos e a circulação internacional de normas democráticas têm imensamente contribuído para a renovação das formas de seleção das elites políticas. Desde então, muitos observadores previram o desaparecimento da transmissão hereditária do poder político. No entanto, essa transmissão hereditária persiste nos regimes monárquicos ${ }^{5}$, que não constituem, entretanto, uma categoria homogênea do ponto de vista das suas regras de sucessão ou do seu funcionamento real, e em certas repúblicas autoritárias (Tunísia, Egito, Síria, Líbia), cujas revoluções árabes mostraram a lógica monárquica e a dificuldade de se transmitir o poder no seio de um clã familiar ${ }^{6}$.

No entanto, a transmissão familiar do poder persiste em sistemas políticos competitivos, onde isso deveria, à priori, parecer paradoxal. Este é o "quebra-cabeça, o enigma" ao qual nosso dossiê é consagrado. De fato, o discurso democrático é baseado na reunião de indivíduos - eleitores e candidatos - cujas famílias deveriam permanecer na esfera privada. Porém, o uso do parentesco tornou possível a instalação de dinastias políticas no topo do Estado e, se as famílias políticas à frente do executivo raramente conseguem sobreviver à terceira sucessão, isso ocorre de forma diferente para as dinastias dos parlamentares ou dos eleitos locais. Constatamos também que, mesmo sem haver a transmissão hereditária do direito, as famílias ocupam posições estratégicas em muitos sistemas políticos competitivos. Além disso, o fenômeno hereditário na política não é específico para apenas uma região do mundo, uma vez que é encontrado na

3 VEYNE, Paul. Império greco-romano, Paris: Le Seuil, 2015.

VATIN, Nicolas e VEINSTEIN, Gilles. O serralho abalado: a sucessão no trono otomano (das origens até o século XIX). Paris: Fayard, 2003

${ }^{4}$ LEWIS, Andrew W. O sangue real: a Família Capetiana e o Estado (França, séculos X-XIV). Paris: Ed. Gallimard, 1986.

${ }^{5}$ Não são aqui consideradas as monarquias simbólicas do tipo britânica.

${ }^{6}$ BROWNLEE, Jason. "Sucessão hereditária em autocracias modernas". In: World Politics, 59 (4), 2007, p. 595-628.

BROWNLEE Jason. "A aparição hereditária de Gamal Mubarak". In: The Arab Studies Journal, 15/16 (2/1), Outono de 2007/Primavera de 2008, p. 36-56. 
América do Norte e do Sul, na Europa, na Ásia, no mundo árabe e na África subsaariana. Ele persiste nos regimes em processo de democratização (dos Bandaranaike no Sri Lanka, Gnassingbé no Togo, Bongo no Gabão) ${ }^{7}$, mas também nas democracias mais estabelecidas (Kennedy, Bush e Clinton nos Estados Unidos, Trudeau e Johnson no Canadá, Le Pen na França, Kirchner na Argentina, Abe no Japão, Gandhi na Índia, Aquino nas Filipinas). Esses fenômenos colocam de forma concreta a questão da renovação das elites e das condições de estabilidade política no seio das sociedades recentemente democratizadas, mas também em democracias já estabelecidas. Para entender as formas contemporâneas de herança política, este dossiê reúne estudos de caso do Sudeste Asiático, da França e do Líbano. Ele convida pensar em fronteiras - mais porosas do que parece - entre experiências democracias poliárquicas e oligárquicas.

Apesar do seu interesse, a dimensão familiar da captura do poder político permanece relativamente inexplorada. Estudos de caso estão disponíveis nos Estados Unidos ${ }^{8}$, Canadá $^{9}$, América Latina $^{10}$, Europa ${ }^{11}$, Ásia ${ }^{12}$, no mundo árabe ${ }^{13}$ e na África subsaariana ${ }^{14}$. Esses estudos procuram rastrear as linhagens familiares

\footnotetext{
${ }^{7}$ Nota tradutora: Bandaranaike, Gnassingbé e Bongo são nomes de famílias. Os autores fornecem exemplos de famílias políticas de cada uma das localidades citadas.

${ }^{8}$ HANSEN, Karen V. e GAREY, Anita Ilta (orgs). Famílias nos EUA: parentesco e política doméstica. Filadélfia: Temple University Press, 1998.

HESS, Stephen. As dinastias políticas da América: de Adams a Clinton. Novo Brunswick: Transação, 1997 (1966).

FEINSTEIN, Brian D. "A vantagem da dinastia: laços familiares nas eleições para o Congresso". In: Quarterly Legislative Studies, 35
} (4), 2010, p. 571-598.

9 LE DUC, Lawrence; MCKENZIE, Judith I. ; PAMMETT, Jon e TURCOTTE, André. Dinastias e interligações presentes na política eleitoral canadense. Toronto: Dundurn Press, 2010.

GAGNON, Jacques. "As grandes dinastias políticas do Quebec ". In: Boletim de História Política, 21 (2), 2013, p. 169-177.

${ }^{10}$ WORNAT, Olga. Rainha Cristina: a vida pública da mulher mais poderosa da Argentina. Buenos Aires: Planeta Cop, 2005. BERNADOU, Vanessa, "Nestor Kirchner: do presidente sem poderes ao chefe hegemônico". In: Critique internationale, 43, abriljunho de 2009, p. 89-107.

11 PATRIAT, Claude e PARODI, Jean-Luc (ors.). Hereditariedade na política. Paris: Ed. Economica, 1992.

JAFFRELOT, Christophe. "Ásia: a democracia à prova do fenômeno dinástico?" In: Arquivo, Crítica internacional, 33, Outubrodezembro de 2006.

BANTIGNY, Ludivine e BAUBEROT, Arnaud. Herdar na política: filiações, gerações e transmissões políticas (Alemanha, França e Itália, séculos XIX- XXI). Paris: PUF, 2011.

12 SHIRAISHI, Saya. Heróis jovens: a família indonesiana na política. Ithaca: Cornell University Press, 2000.

CHHIBBER, Pradeep. "Festas dinásticas: organização, finanças e impacto". IN: Party Politics, 19 (2), 2013, p. $277-295$.

ASAKO, Yasushi; JIDA, Takeshi; MATSUBAYASHI, Tetsuya e UEDA, Michiko "Políticos dinásticos: teoria e evidência no Japão". In: Japanese Journal of Political Science, 16 (1), 2015, p. 5-32.

CHANDRA, Kanchan (org). Dinastias democráticas: Estado, festa e família na política indiana contemporânea. Nova York: Cambridge University Press, 2016.

13 BOUKHAIMA, Sakina. "Bashar al-Assad: crônica de uma sucessão na Síria". In: Mundo Árabe, 169, 2000, p. 164-172.

FERRIE, Jean-Noël. O Egito entre a democracia e o islamismo: o sistema de Mubarak no momento da sucessão. Paris: Caso contrário, 2008.

KOHSTALL, Florian e VAIREL, Frédéric. "As eleições legislativas e presidenciais no Egito de 2005 a 2010". In: Egito/Mundo Árabe, 7, 2010, p. 1-18.

PIERRET, Thomas. Baas e Islã na Síria: a dinastia Assad contra os ulemás. Paris: PUF, 2011.

BROWNLEE, Jason. MASSOUD, Tarek. REYNOLDS, Andrew. "Por que a modesta Colheita?" In: Journal of Democracy, 24 (4), 2013 , p. 29-44. 
que evoluem na esfera da política e do Estado expondo as lógicas familiares de reprodução do poder ao nível local e central ${ }^{15}$. Entretanto, esses estudos pouco questionam os mecanismos concretos da herança política, como por exemplo, as estratégias de legitimação do herdeiro, a transmissão de mandatos e funções, as táticas de densificação das redes de apoio informais.

O dossiê da revista Critique Internationale publicado em 2006 sob a direção de Christophe Jaffrelot ${ }^{16}$ teve o mérito de confrontar a questão da hereditariedade na política desenvolvendo uma abordagem comparativa com os países asiáticos (Índia, Sri Lanka, Japão, Coréia em particular). Os estudos dos casos japoneses e indianos constataram, por exemplo, que a proporção de herdeiros, sob diversas formas, é significativamente elevada nesses dois países, onde o fenômeno teria que ser considerado como uma característica central do sistema político, e não apenas como uma anomalia transitória. $\mathrm{O}$ estudo do caso indiano ${ }^{17}$ enfatizou o papel determinante do partido na escolha do herdeiro (mesmo que ele pertença à família dominante); já no caso japonês se alcançava o melhor sucesso eleitoral os deputados herdeiros, que recorriam aos perfis profissionais e psicológicos específicos ${ }^{18}$. Finalmente, o estudo sobre Sri Lanka mostrou que as disputas das famílias que visavam ganhar o poder refletiram o modelo antropológico subjacente da divisão binária da sociedade ${ }^{19}$. A apresentação desses casos parece excluir a determinação "cultural", mas não chega a propor uma matriz de explicação do fenômeno. Seria por que o fator hereditário na política resiste a qualquer forma de comparação com a diversidade de sistemas sócio-políticos nos quais se desenrola? Ou seria por que ele faz o cientista político navegar em águas turbulentas de um vocabulário político que constantemente serve-se da metáfora de família, parentesco e aliança (herança, herdeiro

BONTE, Pierre ; CONTE, Edward e DRESCH, Paul (orgs.). Emires e presidentes: figuras de parentesco e política no mundo árabe. Paris: CNRS Éditions, 2001.

${ }^{14}$ BERNAULT, Florence e TONDA, Joseph. "Gabão: uma distopia tropical". In: African Politics, 115 (3), 2009, p. 7-26.

DEBAIN, Mathilde. "Crônica de uma vitória segura. De volta à campanha presidencial de 2009 no Gabão". In: African Policy, 115 (3), 2009, p. 27-46.

NIOVA, Jean. "Parentesco e política na imbricação: a construção político-jurídica da sucessão hereditária". In: Polis/Journal Cameroonian of Political Science, 16 (1-2), 2009, p. 41-66.

${ }^{15}$ GARRAUD, Philippe. Profissão: político. A carreira política dos prefeitos urbanos. Paris: L'Harmattan, 1989.

${ }^{16}$ Conforme JAFFRELOT, Christophe, "Ásia: a democracia diante do fenômeno dinástico?" In: Reviste Critique Internationale, № 33, 2006/4, p.111-113

Nota tradutora: Reviste Critique Internationale, № 33, 2006/4. Dossie "Asie: la démocratie à l'épreuve du phénomène dynastique ? “. Disponível em https://www.cairn.info/revue-critique-internationale-2006-4.htm\#summary. Acesso 26.outubro. 2017.

17 Conforme JAFFRELOT, Christophe. "Índia, democracia dinástica ou linhagem democracia?". In: Reviste Critique Internationale, № 33, 2006/4, p.135-152.

18 SEIZELET, Eric. "O patrimônio dos deveres parlamentares no Japão". In: Reviste Critique Internationale, № 33, 2006/4, p.115133.

19 MEYER, Eric. "Bipolaridade e práticas de sucessão na democracia do Sri Lanka". In: Reviste Critique Internationale, № 33 , 2006/4, p. 153-164. 
político, descendência, apadrinhamento, filiação, parricídio, família política, partido irmão) sem nunca fazer dela um local de observação privilegiado da sucessão política? Ou seria por que esse objeto "não convencional" ou "indisciplinado" 20 que é a hereditariedade se choca com os limites da disciplina?

É verdade que a transmissão familiar dos sistemas de valores e do capital militante tem sido amplamente estudado. A família tem sido particularmente trabalhada como um agente de socialização e um espaço de transmissão de capitais na reprodução social das elites e na formação das dinastias ${ }^{21}$. A família também se impôs como um esquema de pensamento transponível dentro do campo da política, daí a ideia de semelhança estrutural entre a esfera familiar e a esfera política ${ }^{22}$. Esses estudos, no entanto, somente questionaram a herança de poder do ponto de vista de mandatos eletivos e nominativos, das funções, das estratégias, das posições políticas e das configurações partidárias ${ }^{23}$.

Nas terras não-ocidentais, a desnaturalização das relações políticas e sociais assimiladas a relações de parentesco ${ }^{24}$ baseou-se em pesquisas sobre História e Antropologia Política ${ }^{25}$ que mostraram que o parentesco contribui para a manifestação e para o exercício do poder através de formas de tribalismo político ${ }^{26}$ e faccionalismo político ${ }^{27}$. Os estudos de "bricolagem" constitucionais e institucionais, agora

\footnotetext{
${ }^{20}$ KALUSZYNSKI, Martine. "A quem pertence a República? Objetos disciplinares, objetos disciplinados. Do convite à hibridização disciplinar". In: FAVRE, Pierre; FILIEULE, Olivier e JOBARD, Fabien. O atelier do cientista político. Paris: La Découverte, 2007, p. 7996.
}

${ }^{21}$ BOURDIEU, Pierre. "Estratégias reprodutivas e modos de dominação". In: Métodos de Pesquisa Científica em Serviço Social. 105 (1), 1994

PINÇON, Michel e PINÇON-CHARLOTTE, Monique. Grandes fortunas: dinastias familiares e formas de riqueza na França. Paris: Payot, 1998.

PINÇON, Michel e PINÇON-CHARLOTTE, Monique. Os guetos de Gotha: como a burguesia defende seus espaços. Paris: Le Seuil, 2007.

22 BOURDIEU, Pierre. "Estratégias reprodutivas e modos de dominação", artigo citado.

23 Essas pistas foram exploradas durante a seção temática intitulada "Hereditariedade e competição política: o paradoxo da transmissão familiar do poder político em sistemas políticos competitivos " que organizamos no Congresso da Associação Francesa de Ciência Política em 2013.

Nota tradutora: disponível em https://f.hypotheses.org/wp-content/blogs.dir/465/files/2012/10/appelst2013def.pdf. Acesso 25.outubro.2017. Páginas 53-55.

${ }^{24}$ BOURDIEU, Pierre. A nobreza do Estado. Grandes escolas e espírito corporativista. Paris: Éditions de Minuit, 1989. HOBSBAWN; Eric e RANGER, Terence. A invenção da tradição. Paris: Amsterdam Publishing, 2006. BONTE, Pierre; PORQUERES, Enric e GENE, Jerome Wilgaux (orgs). $\mathbf{O}$ argumento da filiação nas bases das sociedades europeias e mediterrâneas. Paris: MESH, 2011.

${ }^{25}$ MEAD, Margaret (org). Cooperação e competição entre os povos primitivos. Nova Brunswick: Transação, 2002 (1937).

26 FORTES, Meyer e EVANS-PRITCHARD, Edward. Sistema político africano. Londres/Oxford/Nova York: Oxford University Press, 1970 (1940).

LONSDALE, John. "Etnia moral e tribalismo político". In: KAARSHOLM, Preben e HULTIN, Jan (orgs). Invenções e limites: abordagens históricas e antropológicas para o estudo de etnicidade e nacionalismo.In: IDS Roskilde Occasional, Paper 11, 1994, p. 131-50.

${ }^{27}$ DAHOU, Tarik. Entre parentesco e política: desenvolvimento e clientelismo no Delta do Senegal. Paris: Karthala, 2005. 
abandonados ${ }^{28}$, poderiam ser retomados para a compreensão das estratégias institucionais colocadas pelos líderes políticos que visavam estabelecer o posicionamento dos membros de suas redes familiares.

Pensar sobre a transmissão familiar do capital político exige, portanto, uma abordagem deliberadamente em desacordo com a lógica individualista que se baseia na ideologia democrática, porque essa transmissão requer a mobilização dos conceitos de família, parentesco, aliança, herança, clientelismo. Excedendo as análises sobre a formação de "famílias políticas" (que abordam o partido como uma família), nossa proposta é de questionar a formação de "famílias biológicas" na política que se tornam verdadeiras instituições políticas capazes de se perpetuarem por várias gerações.

Os mecanismos de transmissão de poder, dentro de uma mesma família, conduzem as estruturas políticas, os sistemas partidários, o grau de descentralização e a ideologia dominante (familiarista ou conservadora, por exemplo), por isso escolhemos comparar casos de estudos nacionais que não se encaixam nem nas mesmas áreas geográficas, nem nas mesmas trajetórias sócio históricas. A persistência de notabilidades formando dinastias políticas em espaços sociopolíticos circunscritos (aldeias, pequenas vilas) ou a nível nacional é um fenômeno bastante bana ${ }^{29}$.

Além disso, a existência de formas hereditárias na política não distingue um tipo de regime com relação ao outro (democracia, oligarquia, autocracia), mas permite pelo contrário, apontar os limites da proximidade em termos de regimes políticos. Este dossiê está, portanto, em contradição com a oposição binária entre autoritarismo e democracia que visa identificar as "áreas cinzentas" do hibridismo ${ }^{30} \mathrm{e}$ destacar as interdependências entre os fatos políticos do Norte e do Sul ${ }^{31}$. Assim, nos regimes sob pressão, a eleição é menos importante do que a seleção de candidatos. Isso prova também que o funcionamento dos partidos políticos pode ser afetado pela centralidade das grandes figuras carismáticas (oposição ou não), o que contribui para a construção de um capital familiar. Uma hipótese coerente com os casos aqui estudados é que a transmissão do capital político é facilitada pela fácil conversão de diferentes tipos de capital (econômico e político, em particular). A família, uma instituição que permite a conversão de capital

\footnotetext{
28 VAN DE WALLE, Nicolas. "Democratização na África: um balanço crítico". In: GAZIBO, Mamoudou e THIRIOT, Céline (orgs). Política na África: estado dos debates e pistas de pesquisa. Paris: Karthala, 2009, p. 134-164. VILALON, Leonardo e VONDOEPP, Peter (orgs). O destino das experiências democráticas na África: elites e instituições. Bloomington: Indiana University Press, 2005.

${ }^{29}$ DORRONSORO, Gilles. "Regras e recursos: usos do clã na Vila de Kirazbahce (Turquia)". In: European Journal of Turkish Studies, 4, 2006.

30 DABENE, Olivier; GEISSER, Vincent e MASSARDIER, Gilles (orgs.). Autoritarismos democráticos e democracias autoritárias no século XXI: convergências Norte-Sul. Paris: La Découverte, 2008.

31 HYDE, Susan; ALVAREZ, R. Michael e HALL, Thad (orgs). Fraude eleitoral: detectando e dissuadindo a manipulação eleitoral. Washington/DC: Brookings Institution Press, 2008.
} 
(econômico em escolar, por exemplo) e sua transmissão entre diferentes gerações, estaria assim em posição de se impor no campo político.

Finalmente, adotamos uma ampla concepção da família que permanece suficientemente flexível para abordar a complexidade das representações e das práticas familiares nas sociedades que nos interessa. A instituição família "na prática"32 torna possível pensar na formação de laços familiares dentro de uma dinastia política marcada por um duplo processo: o de acumulação e o de dilapidação do capital político por diferentes gerações.

\section{Disciplinar o objeto hereditariedade?}

O conjunto de artigos desse dossiê demonstra que a hereditariedade na política é um objeto áspero de se trabalhar. Em primeiro lugar, porque ele trata de evitar os lugares comuns que fazem derivar a reflexão sobre a continuidade da saga e, em segundo lugar, porque é necessário fazer escolhas para melhor identificar o objeto de estudo. É menos o parentesco e mais a hereditariedade política entendida como a transmissão do poder dentro de uma mesma família que analisamos. Esta abordagem leva em consideração transmissões objetivas e biológicas, mas também simbólicas e metafóricas do esquema de parentes $\mathrm{Co}^{33}$. A este respeito, a distinção entre hereditariedade política (socialização na política) e herança eletiva (transmissão de um mandato) ${ }^{34}$ são discutidos nos artigos de Victor Marneur, Éric Soriano e Virginie Dutoya, enquanto a diferença estabelecida por C.Jaffrelot no dossiê publicado em 2006 entre política dinástica (construída em torno do status herdado) e política linhagem (sucessão na política por várias gerações) alimenta os textos de V. Dutoya, Ward Vloeberghs e É. Soriano. A partir dessas duas distinções, os autores desse dossiê mostram como a hereditariedade constitui um recurso na competição política. Se V. Dutoya lembra sua importância no acesso para a esfera política na Índia, aponta também seu custo, Éric Soriano demonstra a gênese paradoxal da herança política na Nova Caledônia como uma categoria inventada pelo colonizador francês na década de 1950 visando abrir o sistema político após a abolição do Código do Indigenato.

\footnotetext{
32 LAGROYE, Jacques. "A instituição na prática". In: Swiss Journal of Political Science, 8 (3-4), 2002, p. 114-128.

33 OFFERLE, Michel. "Usos e usura da hereditariedade na política". In: French Review of Political Science, 43 (5), 1993, p. 851.

34 GARRAUD, Philippe, "A cidade como uma herança. Herança familiar e legado político entre prefeitos urbanos". In: PATRIAT, C. e PARODI, J.-L. (orgs.). Hereditariedade na política. op. cit., p. 220.
} 
Para possibilitar uma abordagem comparativa, ao mesmo tempo em que se destaca a singularidade de cada situação, realiza-se um cruzamento de escalas (local, regional, nacional) e temporalidades. As lógicas hereditárias da seleção do pessoal político são, portanto, recolocadas no longo prazo da política e da família, bem como na sua forte ancoragem territorial. A entrada por gênero - a diferenciação e a hierarquização dos sexos - é pouco usada para estudar a herança na política. No entanto, como recordado por V. Marneur e V. Dutoya, ela permite entender como o acesso transgressor das mulheres à política pela família contradiz ao mesmo tempo, tanto a lógica democrática igualitária, quanto a hierarquia familiar.

O que mostra esses estudos? Inicialmente constatam que trabalhar a hereditariedade faz o pesquisador se deparar com um conjunto de obstáculos e restrições de ordem metodológica. A diversidade de abordagens (quantitativas e qualitativas) e as ferramentas para coleta de dados (arquivos, revistas da imprensa, entrevistas semi-estruturadas, questionários, bases de dados) mobilizadas pelos investigadores desse dossiê deram lugar para diferentes formalizações. Em seguida, o exercício da categorização ao qual estão entregues os autores permitiu que eles construíssem figuras típicas ideais do legado político que leva em conta os status, as relações de dominação e a cultura material, bem como os modos de transmissão horizontal (marido/mulher, irmão/irmão) ou vertical (pai-filho/filha, pai/genro).

A partir desta configuração metodológica e categórica, os autores desse dossiê desenvolvem, em seus respectivos campos, dois temas de pesquisa: a família como um lugar de transmissão de capital e de habilidades específicas, e a relação entre herdeiros e eleitores nas eleições.

\section{Formação de dinastias políticas e constituição de um capital político familiar}

O fenômeno hereditário levanta a questão da circulação de capitais dentro das famílias e entre os espaços sociais: como uma relação de poder, pode ela ser objetificada a ponto de se tornar transmissível? O fenômeno hereditário, que parece ir ao encontro da racionalização anunciada por Weber ${ }^{35}$, aproxima as formas patrimoniais do campo econômico que, longe de desaparecerem, parece se acentuarem. Mas, dentro da família onde a acumulação de capital econômico pode ser explicada com bastante facilidade, a transmissão do capital político acumulado é um fenômeno mais complexo e mais instável, talvez porque o capital político seja menos objetivável ${ }^{36}$. Esta questão leva, em particular, a se questionar a socialização dos

\footnotetext{
${ }^{35}$ WEBER, Max. A ética protestante e o espírito do capitalismo. 1ạ edição, 1905. Paris: Gallimard, 2003.

36 GOLLAC, Michel e LAULHE, Pierre. "Os componentes da herança social: um capital econômico e cultural a se transmitir". In: Economics and Statistics, 199-200, 1987, p. 95-105

BOURDIEU, Pierre. "Estratégias e modos reprodutivos de dominação", art. citado, p. 11.

BOURDIEU, Pierre. Senso prático. Paris: Éditions de Minuit, 1994.
} 
herdeiros (e, antes de tudo, sobre a escolha desses últimos), a construção do nome e as estratégias de acesso a mandatos eletivos nacionais e locais.

Os capitais não-político (carismático, econômico, religioso) transmitidos pelas famílias, o são sob certas condições (geração, gênero, primogenitura, dispositivos de transmissão). Os autores articulam as questões de status e de vocação na construção da legitimidade e da aprendizagem das competências políticas. Eles enfatizam, em particular, que a conversão das características individuais em recursos coletivos é o que permite a eleição. As trajetórias dos membros dessas famílias permitem igualmente se questionar a conversão desses capitais entre os diferentes espaços sociais: por exemplo, quais condições devem ser reunidas para que o capital carismático ou econômico de uma família seja investido na política? A resposta refere-se à existência de barreiras (legais ou não) para conversão e abre uma tipologia de famílias estabelecida de acordo com seus capitais iniciais e de suas estratégias de conversão. W. Vloeberghs mostra bem como a porosidade dos campos econômico e político no Líbano - e não a organização confessional - explica a constituição das dinastias políticas, algumas das quais remontam ao século XVIII. Com a análise do caso libanês, constatamos que a acumulação econômica supõe com certa frequência um investimento político, sendo a recíproca menos verdadeira. A contribuição de É. Soriano sobre Nova Caledônia mostra como o sistema político (a colonização) criou as condições para uma transformação do parentesco, que se tornou ativo dentro do campo político através da mediação de um investimento partidário/institucional do qual ele representa a forte dimensão empreendedora. V. Marneur e V. Dutoya também destacam, respectivamente para a Gironde e para a Índia, a importância dos capitais adquiridos tanto na família como na atividade profissional para que se compreenda a trajetória ascendente dos herdeiros.

\section{Qualificar e desqualificar a hereditariedade na política}

Finalmente, a transmissão não tem nada de natural, nem de evidente, ela precisa ser constantemente legitimada. Então, como os governantes tentam impor a família como um modelo legítimo de organização política? Como os governados se reapropriam (ou não) deste registro? A percepção pública da transmissão familiar do poder político e as eleições são os momentos de validação (ou de sanção)

PATRIAT, C. E PARODI, J.-L. (orgs). Hereditariedade na política. op. cit.

PINÇON, Micehl e PINÇON-CHARLOT, Monique. Grandes fortunas: dinastias familiares e formas de riqueza na França, op. cit.

WEBER, Florence; GOJARD, Séverine e GRAMAIN, Agnès (orgs). Despesas familiares. Dependência e parentesco na França contemporânea. Paris: La Découverte, 2003.

BESSIERE, Céline. De geração para geração. Arranjos familiares em Cognac Wineries. Paris: Razões para atuar em 2010.

GOLLAC, Sibylle. "A pedra da disputa. Estratégias imobiliárias familiares na França contemporânea", tese de doutorado, Paris, EHESS, 2011.

GOLLAC, Sibylle. "As ambigüidades dos anciãos do sexo masculino. Transferências patrimoniais e transmissão de status social de geração em geração". In: Revue Française de Sociologie, 54 (4), 2013, p. 709-738. 
cidadã. De acordo com o trabalho da sociologia pragmática, os autores tentaram identificar os registros de justificação mobilizados na competição política, especialmente a eleitoral. Somos eleitos por que somos, ou apesar do fato de sermos, os filhos de nossos pais? O registro familiar (que justifica a transmissão) e o republicano (que o invalida) entram em confronto quando dos momentos eleitorais? Quais são os arranjos institucionais e constitucionais colocados em prática para legalizar ou proibir esta transmissão? Na Nova Caledônia, a introdução das eleições mudou profundamente as lógicas da transmissão e do exercício da autoridade. Na Índia, as cotas e os privilégios de que gozam os membros das dinastias políticas foram fortemente criticados. No Líbano, duas dinastias presentes na política, uma desde o século XIX e outra desde a década de 1980, criaram, ao longo das gerações, estratégias eleitorais que contribuíram para moldar o contexto sociopolítico libanês. A formação e a sobrevivência das dinastias, portanto, levantam a questão do partido político e do sistema partidário que se tornam possíveis. Em princípio, a especialização da política condena uma instituição não especializada como a família. Mas a realidade é mais ambígua porque os partidos - instância central da seleção dos candidatos - operam de acordo com arranjos complexos onde as solidariedades familiares e as retribuições múltiplas influenciam diretamente na densidade das redes que sustentam essas dinastias.

No final, a transmissão dinástica do poder não é incompatível com a funcionamento de sistemas representativos: ela confronta os mecanismos de patrimonialização do poder com lógicas à priori abertas de sucessão e de reprodução de política em sistemas (mais ou menos) competitivos. A sucessão hereditária na política seria assim um fenômeno presente em todos os lugares onde a intensidade sozinha varia. As regras do jogo (acumulação e limites de mandatos, modo de votação, etc.) e o amadurecimento de reflexos democráticos desempenham aqui um papel fundamental. 